\title{
Filmes como instrumento multimodal de aprendizagem na sala de aula de inglês como língua estrangeira
}

\author{
Mônica da Costa Monteiro de Souza \\ PUC - Rio
}

\section{Resumo}

Esse trabalho tem o objetivo de abordar o uso de filmes como instrumento de aprendizagem na sala de aula de inglês como língua estrangeira a partir de uma perspectiva multimodal. Para isso, é feita uma revisão teórica que considera vários autores e suas abordagens a respeito da multimodalidade, assim como uma breve revisão da gramática visual proposta por Kress e Van Leeuwen (1996). Com base nesses pressupostos teóricos, especifico a metodologia e procedo à análise de dados, que incluem um segmento do filme Uma babá quase perfeita (Mrs. Doubtfire) e uma atividade relacionada para prática de Simple Past Tense.

Palavras-chave: Filmes no ensino de inglês, multimodalidade, gramática do design visual

\begin{abstract}
The aim of this paper is to consider the use of movies as a multimodal instrument of learning in the EFL classroom. The theoretical overview of the topic defines multimodality and outlines recent research on the concept, as well as the grammar of visual design proposed by Kress and Van Leeuwen (1996). Based on this theoretical framework, the paper explains the method used for the study and presents the analysis of the data, which include a snippet from the movie Mrs. Doubtfire and a task related to it.

Keywords: Films in English language teaching, multimodality, grammar of visual design
\end{abstract}

\section{INTRODUÇÃO}

Por algum tempo a linguagem verbal tem sido considerada como canal central na interação, ao passo que os canais não verbais têm sido considerados como subordinados a ela (Norris, 2004). No entanto, essa a visão que inquestionavelmente posiciona a linguagem 
verbal como constituinte central limita nosso entendimento da complexidade de uma interação.

Kress e Van Leeuwen (1996) consideram que a linguagem verbal é apenas um dos modos de representação semiótica que pode assumir, ou não, um papel central num determinado momento, em uma situação de comunicação. De acordo com a visão desses autores, o modo de representação não verbal pode estar ou não subordinado à linguagem verbal. Ou ainda, os dois modos de representação agem de forma integral, sem que um modo prevaleça sobre o outro. Kress e Van Leeuwen (1996) argumentam, então, que o componente visual de um texto é uma mensagem estruturada e independentemente organizada, relacionada com o componente verbal, mas não obrigatoriamente dependente dele. Da mesma forma o verbal não depende necessariamente do visual. Cada modo de representação semiótica apresenta, segundo os autores, potencialidades e limitações inerentes, diferentes potenciais para construção de sentido e valores sociais específicos a determinados contextos sociais.

Kress e Van Leeuwen (1996, 2001), assim como Lemke (1998), Norris (2004), Wysocky (2004), Scollon e Levine (2004), Dionísio (2005), assumem que todas as interações são multimodais. Isso significa dizer que, ao interagir, ainda que intuitivamente, as pessoas utilizam e reagem a uma variedade de modos comunicativos. Nesse sentido, Norris (2004), ao desenvolver um modelo de análise da interação, parte da crença que só podemos realmente compreender o processo de comunicação se investigarmos tanto os canais visuais de comunicação quanto os canais verbais.

Nesse sentido é que o filme é considerado como um texto multimodal, isto é, um texto em que vários modos de representação interagem na construção de sentido. Usado como instrumento de aprendizagem na sala de aula de língua inglesa, o filme pode ser considerado um acréscimo aos recursos do professor que deseja aproximar o contexto pedagógico a situações reais de comunicação, nas quais os vários modos de representação semiótica não podem ser desprezados pelos participantes da interação na construção de sentido. 


\section{PRESSUPOSTOS TEÓRICOS}

\section{A linguagem verbal e visual: dois modos de representação semiótica}

É a partir dos anos 80 e 90 que as imagens passam a ganhar cada vez mais importância, fazendo com que muitos estudiosos como Kress e Van Leeuwen $(1996,2001)$ voltem sua atenção ao letramento visual e suas implicações educacionais.

Kress e Van Leeuwen (2001) afirmam que a conscientização a respeito da multimodalidade é um fenômeno recente. Segundo estes autores, numa era quando a monomodalidade prevalecia no âmbito de interesse das teorias de linguagem, a linguagem verbal era considerada central e, portanto, o único meio para comunicação e representação. Obviamente, existiam outros modos de representação, que eram, contudo, considerados como secundários ao modo de comunicação central. E mesmo que, como colocam Kress e Van Leeuwen (2001: 45), uma multiplicidade de modos de representação fossem reconhecidos, cada um deles era tratado de forma monomodal, isto é, como práticas distintas que não se complementavam ou se integravam. Porém, numa época em que a multiplicidade de recursos semióticos está em foco, a questão da multimodalidade passa, ainda que lentamente, a ocupar posição mais central nos estudos de linguagem. Kress e Van Leeuwen (2001: 46) afirmam, então, que na era da multimodalidade, outros modos de representação semiótica, além da linguagem verbal, passam a ser tratados como plenamente capazes de servirem à representação e comunicação. Os autores assumem que a linguagem verbal, tanto falada quanto escrita, pode inclusive funcionar de forma secundária a outros modos semióticos como a linguagem visual, por exemplo.

Kress and Van Leeuwen (1996) defendem a idéia de que o desenvolvimento do letramento visual não está baseado na oposição entre visual e verbal, mas sim na integração entre os dois modos de representação semiótica, uma vez que as imagens desempenham um papel relevante em qualquer esfera pública, seja em anúncios de jornal, revistas, filme, televisão, etc. A intenção desses autores não é promover a idéia de que o modo visual substitua outros, mas chamar atenção ao fato de que as imagens representam um papel tão importante na vida de todos nós, adultos ou crianças, que não podemos mais nos dar ao luxo de deixar de lado a habilidade de entendê-las mais profundamente. 
Sendo assim, se as escolas desejam preparar os alunos adequadamente para a nova ordem semiótica, não podem deixar de incluir o modo visual na construção de conhecimento. Diante disso, a inclusão de filmes como recurso didático para o aprendizado de inglês como língua estrangeira representa um passo a frente dentro dessa nova "paisagem semiótica" (semiotic landscape) descrita por Kress e Van Leeuwen (1996: 33).

Dentro desse contexto descrito pelos autores, o uso do modo visual não é o mesmo do que já foi, há cinquenta anos, nas sociedades ocidentais. Segundo eles, essa nova ordem semiótica é fruto da intensificação das diversidades culturais e linguísticas devido ao multiculturalismo, à mídia eletrônica da comunicação, às tecnologias de transporte e desenvolvimentos econômicos globais. A globalização do capital e da informação dissolve não somente limites culturais e políticos como também limites semióticos. O resultado é, como apontam Kress and Van Leeuwen (1996: 34), uma mudança de lugar da linguagem verbal nas formas públicas de comunicação. A linguagem verbal está deixando de exercer o papel exclusivo de meio de comunicação e passando a ser um dos possíveis meios.

De acordo com essa noção de "paisagem semiótica", se desejamos contribuir em favor da capacitação de nosso aluno e sua inserção nessa nova ordem semiótica, explorar de forma significativa o uso de imagens no contexto pedagógico torna-se fundamental. O filme deixa de ser um meio de entretenimento e passa a ser um meio de informação dentro da sala de aula inglês como língua estrangeira. Ou seja, o filme, considerado como um texto produzido num contexto social real, comunica atitudes e aspectos sociais, define valores e crenças do contexto social dentro do qual foi produzido.

Cope e Kalantzis (2000), ao tratarem de uma pedagogia de letramento que possibilite aos aprendizes desenvolverem suas habilidades e conhecimentos num mundo em constante mudança, optam pelo termo multiletramento e justificam a escolha a partir de dois argumentos. O primeiro está relacionado à multiplicidade dos canais e mídias de comunicação; o segundo, ao crescimento da diversidade cultural e linguística.

Segundo os autores, a noção de multiletramento suplementa uma pedagogia de letramento tradicional, voltada apenas para linguagem verbal, que, numa visão autoritária, é concebida como um sistema de regras estável. Uma pedagogia de multiletramento abrange modos de representação que incluem não apenas a linguagem verbal, que, nessa perspectiva, varia de acordo com o contexto social e cultural. A linguagem, de acordo com 
essa proposta de Cope e Kalantzis (2000), assim como outros modos de representação, é um recurso dinâmico de representação usado para uma multiplicidade de propósitos.

Ainda a respeito da questão do letramento visual, vale ressaltar que autores como Rose (2001) acreditam ser o visual o mais fundamental dos sentidos: a criança é capaz de ver antes mesmo de falar, é dessa forma que ela começa a construir seu conhecimento de mundo. A autora aponta o termo "ocularcentrismo" (ocularcentrism) para descrever a centralidade do aspecto visual na vida ocidental contemporânea. Novas formas de conhecimento, portanto, implicam saber olhar. Nós estamos cercados de diferentes tipos de tecnologias visuais, que incluem fotografia, filme, vídeo, gráficos digitais, televisão, etc, e todas essas diversas formas de tecnologia oferecem visões de mundo (Rose 2001:26). Nesse sentido, o conhecimento no mundo moderno e pós-moderno depende de que o indivíduo construa sentido daquilo que o cerca a partir de sua capacidade de olhar.

$\mathrm{Na}$ medida em que a prática pedagógica deve ser revista de modo a incorporar a prática do letramento visual, a sala de aula passa a ser vista como um espaço complexo onde há integração de diversos modos de representação. Ou seja, a sala de aula deve ser considerada um espaço semiótico (Stein, 2000) no qual o aprendiz tem acesso a uma variedade de textos multimodais - visuais, escritos, falados.

O uso de filmes nesse contexto pedagógico pode ser percebido como uma possiblidade de atender, em parte, essa necessidade de uma pedagogia multimodal. O filme como recurso didático gera significados que operam além do linguístico, na medida em que incorpora uma variedade de modos de representação que incluem o visual, oral, escrito.

O uso de filmes como recurso didático está de acordo com que Stein (2000) descreve como "redimensionando recursos" (re-sourcing resources). Segundo a autora, esse processo ocorre quando fazemos uso de recursos já comumente aceitos em determinado contexto em um novo contexto situacional com o objetivo de produzir novos significados. Esta é, a meu ver, uma forma de se considerar o uso de filmes como recurso didático, já que há uma rearticulação daquilo que originalmente é produzido para entretenimento (seja no contexto de uma sala de cinema ou em casa) para o contexto de sala de aula de inglês como língua estrangeira com o objetivo pedagógico. Pode-se dizer que se trata de duas práticas sociais que estruturam de forma diferente a maneira de assistir o filme. 
A respeito disso, Rose (2001: 26) argumenta sobre a importância de se levar em consideração a questão da "mobilidade das imagens". Segundo a autora, atualmente, imagens aparecem e reaparecem em todos os tipos de lugares, e esses lugares mediam os efeitos visuais das imagens e implicam diferentes maneiras de assistir. Rose (2001) argumenta que um cinema, uma televisão numa sala de estar e uma galeria de arte não pressupõem a mesma maneira de assistir. Da mesma forma, pode-se dizer que a sala de aula, considerada como espaço onde se relacionam a prática social e pedagógica, media o efeito visual dos filmes de forma diferente do que ocorre no cinema ou mesmo na televisão em casa.

É interessante também considerar aqui a distinção entre "visão" e "visualidade" (vision e visuality) da maneira como é descrita por Rose (2001:26). A autora considera que "visão" é o que o olho humano é capaz de ver. "Visualidade", por outro lado, refere-se ao modo através do qual a visão é construída, que inclui como nós vemos, como nós somos capazes, permitidos, ou levados a ver. Ou seja, tanto aquilo que é visto quanto a forma como é visto são social e culturalmente construídos. Uma vez que lançar um olhar a uma imagem sempre acontece dentro de um contexto social, as práticas sociais específicas de um dado contexto implicam diferentes expectativas no que diz respeito ao comportamento do espectador. Esses aspectos referentes à "visualidade" irão, segundo a autora, afetar a maneira como a imagem é vista.

Trabalhando o uso de filmes numa sala de aula, podemos dizer, então, que o aspecto da "visualidade" não será construído da mesma maneira que em outros ambientes sociais como no cinema, por exemplo, já que se tratam, como mencionado anteriormente, de duas práticas sociais diferentes. Em outras palavras, no contexto pedagógico, o uso de filme deve ser concebido, acima de tudo, como um instrumento de aprendizagem que, numa perspectiva multimodal, permite ao aluno o desenvolvimento de suas competências no que diz respeito ao uso da língua que está sendo aprendida.

Dionísio (2005: 172) afirma que "todo professor tem convicção de que imagens ajudam, quer seja como recurso para prender a atenção dos alunos, quer seja como portador de informação complementar ao texto verbal". A autora reconhece que, na era de avanços tecnológicos como a que vivemos, os textos visuais nos cercam em todos os contextos 
sociais e, consequentemente, os materiais didáticos utilizam cada vez mais uma diversidade de gêneros textuais, que incluem também uma variedade de imagens.

Diante de tal cenário, Dionísio (2005: 173) registra a necessidade de se considerar a Teoria da Cognição da Aprendizagem Multimídia - TCAM - (Mayer, 2001). De acordo com essa teoria, os alunos aprendem melhor através de palavras e imagens do que palavras apenas (Principio da Multimídia). Partindo da crença que se devem explorar meios que vão além do puramente verbal, o autor propõe a noção de aprendizado multimídia (multimedia learning), que se refere ao aprendizado que envolve apresentação de material usando palavras e figuras. Mayer (2001: 2) considera que assistir um vídeo pode ser considerado como uma experiência multimídia, já que incluem imagens e sons.

Sendo assim, Dionísio (2005) propõe que a TCAM pode ser inserida na elaboração e análise de materiais didáticos como suporte para o tratamento da multimodalidade no contexto de ensino-aprendizagem. O meu interesse, ao fazer uso de filmes como instrumento de aprendizagem, é facilitar o aprendizado e, portanto, a cognição humana através de recursos tecnológicos que estão ao meu dispor na sala de aula. Dessa forma, ao valorizar o uso de filmes como recurso didático, estou apresentando uma proposta consistente com a TCAM, pois não estou preocupada em permitir aos alunos acesso às últimas tecnologias que decoram o contexto de sala de aula, mas, ao contrário, usar a tecnologia que disponho na sala de aula para facilitar a construção do conhecimento.

\section{A gramática visual}

Kress e Van Leeuwen (1996, p.39) apresentam uma série de hipóteses de acordo com as quais os seres humanos usam uma variedade de modos de representação para a construção de sentido. Esses diferentes modos de representação não podem ser considerados separadamente, como domínios autônomos no cérebro, ou como recursos de comunicação autônomos em uma cultura; ao contrário, os diferentes modos de representação devem ser percebidos de maneira interrelacionada. Proposição semelhante é discutida por Lemke (2002 apud Braga 2004, p.148):

\footnotetext{
"as representações verbais e visuais co-evoluiram histórica e culturalmente para complementarem-se mutuamente e para serem co-ordenadas e co-integradas. Cada forma semiótica é única na medida em que agrega um conjunto de normas interpretativas e possibilidades de significado que lhes são particulares".
} 
Dentro de um contexto teórico denominado de Semiótica Social, e com o objetivo de facilitar a integração dos aspectos visuais e verbais no processo de ensino/aprendizado, Kress e Van Leeuwen (1996) propõem, então, uma teoria de gramática visual consistente com a proposta da linguística sistêmico-funcional de Halliday (1994). Segundo Kress e Van Leeuwen (1996), as imagens não são estruturadas do ponto de vista meramente formal, mas sim a partir de uma dimensão semântica, isto é, as imagens não são construídas aleatoriamente; ao contrário, existem propósitos semânticos que podem ser identificados.

No modelo linguístico sistêmico-funcional de comunicação de Halliday (1978), esses propósitos podem ser interpretados em termos de três metafunções: ideacional (introduzindo conteúdo informacional relativo a determinado assunto, relaciona-se à natureza do evento, aos objetos e participantes envolvidos, e às circunstâncias em que eles aparecem), interpessoal (envolvendo relações sociais entre interactantes) e textual (referente à distribuição da informação do ponto de vista da composição).

De acordo com a hipótese sistêmico-funcional, Kress e Van Leeuwen (1996) argumentam que em todo processo de construção de sentido, seja a partir de imagens ou da linguagem verbal, são desempenhadas essas três metafunções, as quais Halliday (1978) nomeou de ideacional, interpessoal e textual.

É, portanto, à luz da teoria da gramática visual proposta por Kress e Van Leeuwen (1996) e concebida num ambiente teórico denominado Semiótica Social, que se procede à análise das imagens dos segmentos de filmes que compõem parte dos dados dessa pesquisa.

\section{METODOLOGIA}

Nesse trabalho, a análise de dados focaliza os significados ideacionais (experienciais) encontrados nos filmes considerados como instrumentos multimodais de aprendizagem. O segmento de filme que faz parte da análise desse trabalho é uma cena de "Uma babá quase perfeita" (Mrs. Doubtfire) que se encontra no link http://www.youtube.com/watch?v=7X9K3j0UHpM. Esse segmento foi escolhido porque apresenta uma cena bastante significativa do ponto de vista da multimodalidade. Além disso, podemos relacionar a ele uma atividade que pratica o simple past tense, estrutura verbal de fundamental importância para o aprendiz de inglês. 
A opção de análise do segmento de filme focaliza os significados ideacionais relacionados à imagem. Essa mesma opção metodológica faz parte também do trabalho de Royce (2002) e é justificada pelo fato de o filme ser considerado um texto multimodal dinâmico que utiliza, tanto o código da composição espacial como da composição temporal (Kress e Van Leeuwen 1996: 183). Esses autores, ao analisarem textos multimodais, optam por textos que incluem figuras, gravuras, fotografias, que utilizam o código da composição espacial. Nesse caso, a análise proposta por eles inclui as três metafunções: ideacional (representacional), interpessoal (interativa) e textual (composicional). No entanto, uma vez que essa pesquisa analisa imagens dinâmicas, deve-se reconhecer que os significados dependem, mais do que de enquadramentos individuais, de uma sequência de imagens que incluem som e música em processos narrativos. A respeito disso, Wysocki (2004: 136) chama atenção ao fato de que, quando analisamos vídeo, devemos ter em mente a vasta gama de aspectos que estão relacionados à produção de imagens, tais como: enquadramento, luz, cor, transições entre sequências, legendas e até mesmo o fato de os atores dirigirem-se ou não à câmera, entre outros.

Ao considerar o segmento de filme que faz parte dos dados dessa pesquisa, analiso, então, as características ideacionais fazendo um paralelo (cf. Kress e Van Leeuwen, 1996) com as categorias funcionais propostas por Halliday (1994): participantes, processos, circunstâncias e atributos. Para isso, levo em consideração o seguinte: 1- identificação: quem ou o que são os participantes representados, quem ou o que está na moldura visual (animado ou inanimado); 2- atividade: que processos existem, ou que ações estão acontecendo entre ator(es) e recipiente(s) ou objeto(s) dessa ação; 3- circunstâncias: quais são os elementos que dizem respeito ao lugar, companhia (participantes não envolvidos com a ação) ou meio (participantes usados pelos atores); 4- atributos: qualidades e características dos participantes. Esses elementos constituem o que Royce (2002) denomina de "elementos visuais da mensagem" (visual message elements - VMEs).

O próximo passo para análise do filme enquanto recurso multimodal é considerar que tipo de tarefa, no nível da linguagem verbal, pode estar relacionada a essa imagem e, consequentemente, a esses elementos visuais da mensagem. A tarefa que acompanha o segmento de filme é de fundamental importância no que diz respeito ao objetivo de aprendizado que se visa alcançar como o uso desse segmento. Além disso, a necessidade 
de inclusão de uma tarefa está também de acordo com a TCAM (Mayer, 2001), no que diz respeito à pressuposição de uma capacidade limitada da mente humana para o processamento da informação, isto é, Mayer (2001) atesta que os seres humanos têm limitações quanto à quantidade de informação que pode ser processada pelos canais de processamento visual e verbal.

Segundo o autor (2001: 49), quando uma ilustração ou animação é apresentada, o aprendiz é capaz de reter apenas algumas das imagens na sua memória de trabalho. Essas imagens refletem porções do material apresentado e não uma cópia exata desse material. Por isso, é fundamental que as mensagens instrucionais relacionadas aos segmentos de filme sejam organizadas de forma a permitirem um engajamento do aprendiz de forma produtiva do ponto de vista cognitivo. As atividades propostas a partir do uso de filmes devem, portanto, ajudar o aluno a fazer sentido do material apresentado, relacionando-o a um objetivo específico de aprendizado. Em outras palavras, as tarefas propostas em conjunto com os segmentos de filmes devem ajudar o aluno no processamento cognitivo da informação, focalizando a sua atenção a partes específicas da imagem, e, consequentemente, ajudando na organização da informação que é processada.

No entanto, vale lembrar novamente que a escolha do material a ser trabalhado em sala de aula, isto é, o segmento de filme e tarefa que o acompanha, não é arbitrária. Ao contrário, essa escolha tem fundamentação pedagógica e está relacionada a um objetivo dentro do processo de aprendizado. No caso desse trabalho, a tarefa e o segmento de filme analisados tem o objetivo de praticar o Simple Past Tense.

Para a análise do tipo de tarefa proposta em parceria com o uso de filmes, baseio-me na proposta de Ticks (2005). A autora propõe uma análise de atividades a partir de Kumaradivelu (1994) e sua classificação de metodologias e abordagens de ensino em três grandes grupos: centradas na linguagem (gramática-tradução, audiolingual, cognitive code learning), centradas na aprendizagem (direto, suggestopedia, the silent way, total physical response, natural) e centradas no aprendiz (communicative language teaching). Ticks (2005), então, propõe três grupos de atividades ou tarefas: 1- centrados na linguagem, porque baseiam-se as teorias cujo foco é a forma da língua; 2- centrados na atividade, porque estão coerentes com as propostas que estabelecem atividades abertas, conhecidas 
como open-ended, e focalizam a negociação de signficados; e 3-centrados na função, porque procuram trabalhar atividades que realizam funções da linguagem.

As atividades centradas na linguagem promovem oportunidades para os aprendizes trabalharem estruturas linguísticas (léxico-gramaticais) pré-selecionadas, pré-sequenciadas, através de exercícios que focalizam a forma. Já as tarefas centradas na atividade promovem oportunidades para que o aprendiz participe de interações abertas, levando em consideração a negociação de significados como proposta de aprendizagem. A terceira categoria, centrada na função, dá oportunidade ao aluno de praticar estruturas pré-selecionadas, présequenciadas, focalizando, além da forma, propriedades funcionais e nocionais da linguagem.

\section{ANÁLISE DE DADOS}

Dois tipos de dados estão sendo contemplados no presente trabalho: o segmento do filme Uma babá quase perfeita (Mrs. Doubtfire) e a atividade para a prática de Simple Past Tense que acompanha esse segmento (conforme Quadro 1).

\section{Segmento/tarefa 1 (DVD faixa 1) - Uma babá quase perfeita (Mrs. Doubtfire)}

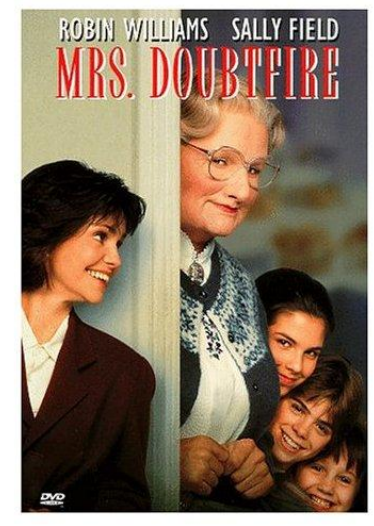

Quanto a este segmento, a análise permite identificar os seguintes elementos da mensagem visual em relação à tarefa proposta: 


\section{Participantes}

Mrs. Doubtfire/Daniel, bicicletas, carpete, TV, cerveja, lagosta, livro (Stuart Little),vassoura, bola, casa

\section{Atividades}

jogar, pedalar, limpar, beber, assistir, cozinhar, ler, tocar, dançar, andar

\begin{tabular}{|l|}
\hline Circunstâncias \\
\hline Lugar \\
\hline rua, sala \\
\hline
\end{tabular}

É interessante notar que o participante bola pode também funcionar como meio, dependendo da maneira como é considerada a imagem. Ou seja, se consideramos que Mrs. Doubtfire e o menino jogam futebol, a bola é uma circunstância de meio; se considerarmos que eles chutam a bola, ela passa a ser um participante objeto da ação. De forma semelhante, a vassoura, quando usada com a finalidade de limpeza, deve ser considerada instrumento; quando usada como guitarra, passa a ser participante.

As pessoas e o cachorro que podem ser percebidos no parque e na rua, apesar de desempenharem atividades, fazem parte do pano de fundo da cena e não interagem ou mantêm relação direta com os participantes principais, por isso considero que fazem parte do cenário e constituem circunstâncias de companhia.

Pode-se notar que existem bastantes atributos a serem identificados no segmento em questão. Entretanto, para completar a tarefa relacionada, não é necessária referência direta a eles, pois, como poderá ser observado a seguir, a tarefa em questão focaliza a prática da estrutura verbal Simple Past Tense, e, por essa razão, está especialmente relacionada aos participantes e processos, que, juntamente com as circunstâncias de lugar acima citadas, são, em relação à tarefa, os elementos da mensagem visual mais relevantes. Esse segmento é, de fato, bastante rico no que diz respeito às atividades/ações. Em pouco mais de dois 
minutos, podemos observar mais de vinte processos diferentes. Por essa razão, o segmento torna-se proveitoso para se explorar estruturas léxico-gramaticais relacionadas a verbos e/ou tempos verbais, e é exatamente isso que a tarefa sugerida tem o objetivo de trabalhar.

A análise da tarefa (Quadro 1) que acompanha o segmento de filme mostra que essa é uma atividade do tipo centrada na linguagem. Trata-se de uma tarefa que tem o objetivo de praticar a estrutura linguística do Simple Past Tense, isto é, o foco da atividade é trabalhar uma estrutura léxico-gramatical pré-selecionada e, portanto, focalizar a forma.

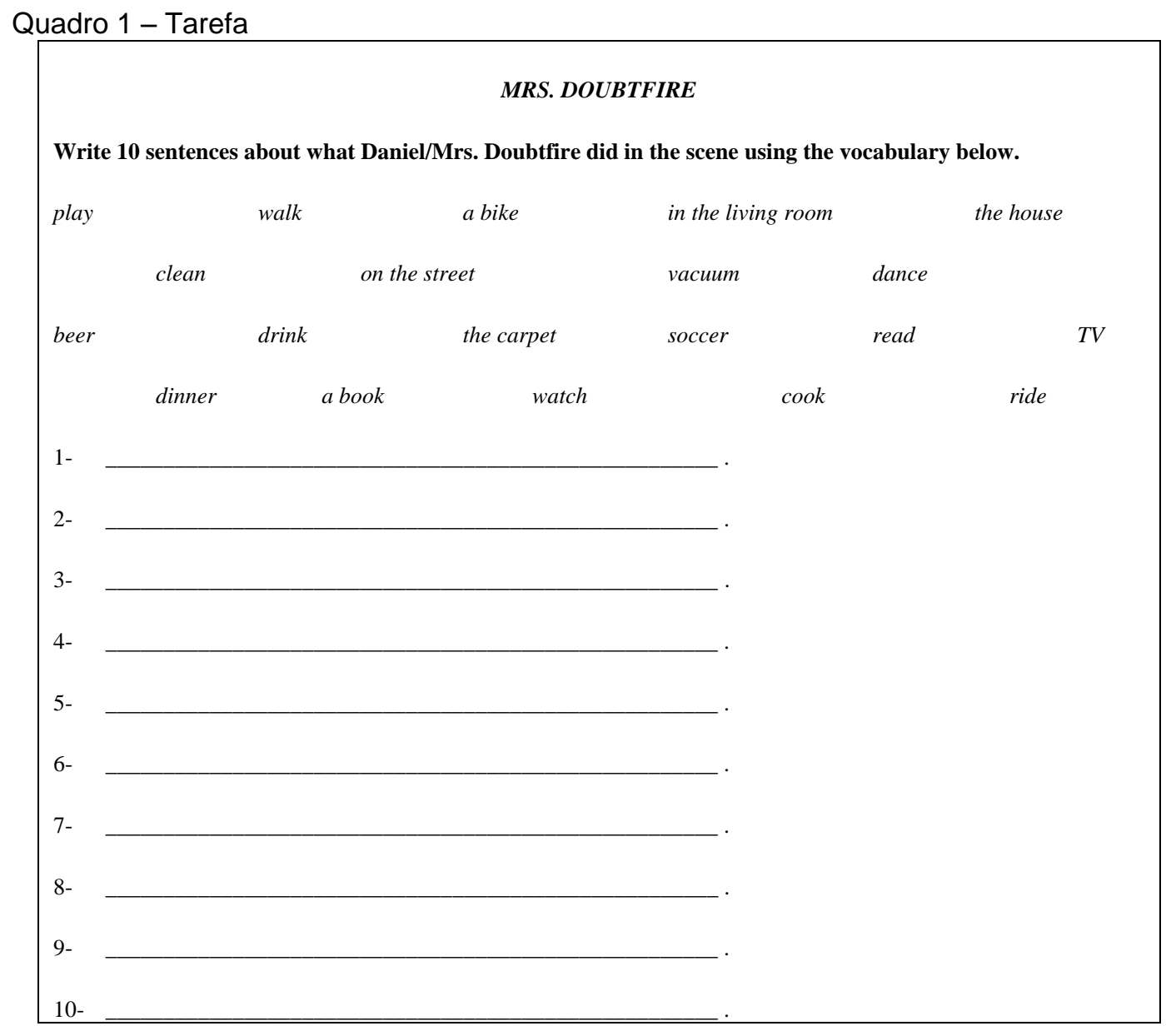

Os passos para realização dessa tarefa na sala de aula são os seguintes:

1- os alunos assistem o segmento de filme, prestando atenção, em especial, ao que acontece; 
2- $\quad$ após assistirem o segmento, a tarefa é, então, distribuída pelo professor, que confere/ elicita as instruções, que dizem respeito a construção de enunciados no Simple Past Tense referentes ao que foi realizado pelo personagem de Daniel/Mrs. Doubtfire;

3- os alunos conferem se o vocabulário que devem usar para construção dos enunciados está claro, e, se necessário, o professor pode referir-se a cena, já que esta apresenta visualmente todos esses participantes, processos e circunstâncias;

4- finalmente, os alunos, individualmente ou em pares, devem produzir dez enunciados usando o vocabulário dado e os verbos no Simple Past Tense para descrever o segmento assistido.

Esta breve análise de dados permite mostrar que filmes podem ser usados como um recurso multimodal de aprendizagem na sala de aula de inglês como língua estrangeira. O filme é um instrumento mediador de significados que faz com que os alunos interajam de diferentes formas frente aos vários modos de representação semiótica, como linguagem oral, escrita, imagens, movimentos e sons. É verdade que existem diversas maneiras de se explorar a multimodalidade no contexto pedagógico, mas compartilho uma possibilidade que tem demonstrado bastante sucesso no contexto de ensino de inglês como língua estrangeira. Acredito que a implementação da proposta desse trabalho no contexto pedagógico pode facilitar o conhecimento de certas características do sistema e do uso da língua, vista como fenômeno multimodal.

\section{CONSIDERAÇÕES FINAIS}

Esse trabalho considera o filme, no contexto de sala de aula de língua estrangeira, a partir de uma perspectiva multimodal, isto é, o filme é um texto em que vários modos de representação interagem na construção de sentido.

Assume-se que a linguagem verbal é apenas um dos modos de representação semiótica que pode assumir papel principal num determinado momento de uma interação. Logo, todas as interações são consideradas multimodais, ou seja, toda interação implica 
uma multiplicidade de modos comunicativos, o que torna impossível construirmos sentido de uma mensagem se levarmos em conta apenas um sistema de recurso semiótico.

Observou-se que, na vida ocidental contemporânea, o aspecto visual vem desempenhado papel central e, logo, que os papéis desempenhados pelas imagens são múltiplos e complexos. Em consequência da crescente importância da comunicação visual no mundo contemporâneo, a necessidade de desenvolvimento do letramento visual e suas implicações educacionais passam a ser discutidas. O contexto pedagógico, diante disso, deve estar preparado para capacitar adequadamente o aprendiz para a nova ordem semiótica, incluindo e explorando de forma significativa o modo visual no processo de construção de sentido. A sala de aula passa a ser vista como um espaço semiótico, e adotase uma pedagogia com orientação multimodal, o que faz necessário que professores voltem cada vez mais sua atenção a recurso tecnológicos da sociedade moderna que podem ser inseridos nas atividades realizadas em sala de aula.

Considera-se também a Teoria da Cognição de Aprendizagem Multimídia (TCAM), que propõe que os alunos aprendem melhor através de palavras e imagens do que palavras apenas.

Diante de tal cenário, torna-se fundamental explorar de forma significativa o uso de imagens no contexto pedagógico. Vejo, então, a inclusão de filmes como recurso didático para o aprendizado de inglês como língua estrangeira como um gesto a favor dessa nova ordem semiótica. O uso de filmes no contexto pedagógico pode ser percebido como uma maneira de atender a necessidade de uma pedagogia multimodal, uma vez que incorpora uma variedade de modos de representação que incluem o visual, oral, escrito.

Os filmes surgem, portanto, como uma possibilidade valiosa de servirem como instrumento multimodal de aprendizagem que pode auxiliar tanto professores quanto alunos a transformarem a sala de aula em um local que abre caminho para o desenvolvimento.

Contudo, cabe a cada um de nós, enquanto profissionais conscientes de nossa prática, avaliar que recursos podemos implementar em nossa sala de aula, vista aqui como ambiente multimodal propiciador de interação, ou ainda, um meio ambiente social, em que a aprendizagem deve fazer parte de nossas experiências de participação vividas no mundo. 


\section{REFERÊNCIAS}

Dionísio, A. P. (2005). "Gêneros Multimodais e Multiletramento". In: Karwoski, A.M.; Gaydeczka, B.; Brito, K.S (orgs.) Gêneros Textuais: reflexões e ensino. Palmas e Uniso da Vitória, PR: Kaygangue.

Halliday, M. A. K. (1978). Language as social semiotic: the social interpretation of language and meaning. London: Arnorld.

(1994). An Introduction to Functional Grammar. London: Edward

Arnold.

Kress, G. (2000). Rethinking Resources in the ESL Classroom. Multimodality: Challenges to Thinking About Language. TESOL Quarterly, vol. 34, No. 2, 337-340.

Kress, G. \& Van Leeuwen, T. (1996). Reading Images: The grammar of visual desing. London, Routledge.

(2001). Multimodal Discourse: The Modes and Media of

Comtemporary Comunication. London: Arnold.

Kumaravadivelu, B. (1994). The Post-method Condition: (E)merging Strategies for Second/Foreign Language Teaching. TESOL Quaterly, Vol. 28, No. 1, pp. 27-48.

Mayer, R.E. (2001). Multimedia Learning. Cambridge: Cambridge University Press.

Norris, S. (2004). Analysing Multimodal Interaction. London, UK: Routledge

Rose, G. (2001). Visual Methodologies: An Introduction to the Interpretation of Visual Materials. SAGE Publications Ltd.

Royce, T. (2002). Mutimodality in the TESOL Classroom: Exploring Visual-Verbal Synergy. TESOL Quarterly vol. 36, No. 2, 191-205.

Scollon, R. \& Levine, P. (2004). "Multimodal discourse analysis as the confluence of discourse and technology". In: Levine, P.\& Scollon, R. (eds) Discourse and technology: Multimodal discourse analysis. Washington, DC: Georgetown University Press.

Stein, P. (2000). Rethinking Resources in the ESL Classroom. Rethinking Resources: Multimodal Pedagogies in the ESL Classroom. TESOL Quarterly, vol. 34, No. 2, 333-336.

Ticks, L. K. (2005). O livro didático sob a ótica do gênero. In Linguagem \& Ensino, vol. 8, No. 1 (15-49).

Van Leeuwen, T. (2004). "Ten reasons why linguistis should pay attention to visual communication”. In: Levine, P; Scollon, R (eds.) Discourse and technology: multimodal discourse analysis. Washington, DC: Georgetown University Press. 
Wysocki, A.F. (2004). The multiple media of texts: How onscreen paper texts incorporate words, images, and other media. In: Bazerman, C. \& Prior, P. (eds) What writing does and how it does it: an introduction to analyzing texts and textual practices. Mahwah, N.L.: Lawrence Erlbaum.
A AUTORA
Mônica da Costa Monteiro de Souza graduou-se em Letras, com bacharelado em português-inglês na PUC-Rio em 1991 e licenciatura em inglês e literaturas da língua inglesa na UERJ em 1992. Cursou a especialização lato-sensu em língua inglesa na PUC- Rio em 1992. Mestre em Letras - Estudos da Linguagem - pela PUC-Rio em 2007.
E-mail: monicacmsouza@globo.com 